\title{
Biomechanical Features of Drop Vertical Jump Are Different Among Various Sporting Activities
}

\author{
Kengo Harato ( $\nabla$ harato@keio.jp ) \\ Keio University School of Medicine \\ Yutaro Morishige \\ Keio University School of Medicine \\ Shu Kobayashi \\ Keio University School of Medicine \\ Yasuo Niki \\ Keio University School of Medicine \\ Takeo Nagura \\ Keio University School of Medicine
}

\section{Research Article}

Keywords: Drop vertical jump, Sport-specific movement, Anterior cruciate ligament, Female athletes, Biomechanics

Posted Date: November 18th, 2021

DOl: https://doi.org/10.21203/rs.3.rs-957277/v1

License: (c) (i) This work is licensed under a Creative Commons Attribution 4.0 International License. Read Full License

Version of Record: A version of this preprint was published at BMC Musculoskeletal Disorders on April 8th, 2022. See the published version at https://doi.org/10.1186/s12891-022-05290-0. 


\section{Abstract}

Background: Risk for non-contact anterior cruciate ligament (ACL) injury can be assessed based on drop vertical jump (DVJ). However, biomechanics of DVJ should differ with type of various sporting activities. The purpose of the present study was to clarify whether biomechanical features of DVJ are different among various sporting activities in female athletes.

Methods: A total of 42 female athletes, including 25 basketball, 8 soccer and 9 volleyball players, participated in the current investigation. DVJ was done for each female athlete using a three-dimensional motion analysis system which consisted of six cameras, two force plates and 46 retro-reflective markers. Kinematic and kinetic data were recorded for both limbs in each athlete. Simultaneously, frontal and sagittal plane views of the DVJ were recorded using high-resolution two different video cameras to evaluate Landing Error Scoring System (LESS) score. Three-dimensional biomechanical parameters at the knee joint and LESS were compared among three different sporting activities.

Results: Soccer players had better LESS score, compared to basketball players, while no significantly differences were found between basketball and volleyball players in LESS. In addition, peak knee flexion angle was significantly larger, and knee abduction angle at initial contact (IC), peak knee abduction angle, knee internal rotation angle, and knee abduction moment within 40 milliseconds from IC were significantly smaller in soccer players, compared to basketball players. There were no significantly differences between basketball and volleyball players in all biomechanical parameters.

Conclusions: From the present study, female basketball and volleyball players have worse LESS score, greater knee abduction angle and moment, compared to female soccer players. Thus, female basketball and volleyball players are likely to have the increased risk of non-contact ACL injury during DVJ, compared to soccer players. DVJ may be useless as a screening tool of non-contact ACL injury for soccer players. Biomechanics of DVJ depends on characteristics of the athlete's primary sport.

\section{Background}

Young female athletes are prone to have non-contact anterior cruciate ligament (ACL) injuries. Clinically, non-contact episode includes deceleration, lateral pivoting, or landing tasks which are associated with high external knee joint loads. According to previous literatures, drop vertical jump (DVJ) can be a useful screening tool to evaluate the risk for non-contact $A C L$ injury in female athletes [1-18]. Athlete drops from a wooden box, lands, and performs a vertical jump as soon as possible as DVJ. Based on biomechanical data, an algorithm has been designed using the DVJ to evaluate the risk for non-contact ACL injury. The DVJ has thus been used to assess the risk for non-contact ACL injury in many studies [1, $3,4,13-16,19-21]$. For example, Hewett et al. suggested that female athletes with larger knee abduction angle at initial contact (IC), peak knee abduction angle, and peak knee abduction moment during DVJ would be prone to non-contact ACL injury [1]. On the contrary, Krosshaug et al. indicated that DVJ should be a poor screening tool for non-contact ACL injuries from a prospective cohort study [19]. Although it is 
still controversial whether DVJ is an important clinical tool of ACL injury or not, little attention has been paid to the biomechanical differences of DVJ among various sporting activities. Therefore, the most appropriate type of sport for DVJ screening is unknown so far.

The purpose of the current study was to clarify whether the characteristics of the various sporting activities in female athletes would affect the biomechanics of DVJ. It was hypothesized that biomechanical features would depend on the athlete's primary sport.

\section{Methods}

\section{Participants}

A total of 42 female college athletes, including twenty-five basketball players, eight soccer players and nine volleyball players, were enrolled in the present study. Tegner activity scales were 7 to 9 . All of subjects were member of college sports team and their practice was longer than 18 hours a week. None of the athletes had any history of major injuries or surgeries to the trunk and lower extremities. A written informed consent form approved by Institutional Review Board of our university was obtained from each athlete.

\section{Test Procedures}

The jump-landing biomechanics during Drop Vertical Jump (DVJ) was examined. Subjects were asked to perform DVJ, from a $30 \mathrm{~cm}$ high box forward to a distance of $50 \%$ of their height away from the box, and immediately jump vertically as high as possible. Before data collection, instructions were done to perform DVJ. After performing DVJ several times as warm-ups, three successful trials were recorded for each athlete. DVJ was captured using a three-dimensional motion analysis system consisted of six cameras (120 frames/s; Oqus, Qualisys, Sweden), two force plates (frequency $600 \mathrm{~Hz}$; AM6110, Bertec, Columbus, $\mathrm{OH}, \mathrm{USA}$ ), and 46 retro-reflective markers (14mm in diameter). The force plate collected ground reaction force (GRF) data at $600 \mathrm{~Hz}$ and were synchronized to the camera sampling rate of $120 \mathrm{~Hz}$. The time at initial contact (IC) and toe-off (TO) form the jump were identified based on GRF data. Markers were placed on anatomic landmarks and specific locations. A set of anatomical landmarks were defined as follows; spinous process of vertebra at the level of $C 7$ and Th 10, jugular notch and xiphoid process of sternum, acromion, anterior superior and posterior superior iliac spine, greater trochanter, medial and lateral femoral epicondyles, medial and lateral malleoli, head of first and fifth metatarsal bone, scaphoid, and calcaneus. Additional specific markers were placed on the frontal and lateral aspects of thigh (4 markers) and shank (4 markers). The set of markers was used to calculate joint centers and segment positions in standard quiet stance, and to track segment motion during the DVJ tests. Joint angles were calculated based on the cardan sequence of $X Y Z$, equivalent to the joint coordinate system.

For each athlete, three-dimensional kinematic, kinetic and GRF data were assessed bilaterally during IC to TO. Marker movements were recorded by Qualisys Track Manager Software (version 2.7). To calculate 
biomechanical parameters at the knee joint, Visual 3D (C-motion Company, Rockville, MD) was used (Fig. 1). As kinematic parameters, knee flexion angle at IC, peak knee flexion angle (IC-TO), knee abduction angle at IC, peak knee abduction angle (IC-TO), knee internal rotation angle at IC, and peak knee internal rotation angle (IC-TO), were adopted. Knee internal rotation was defined as tibial rotation with respect to the femur. As kinetic parameters, peak knee flexion, abduction, internal rotation moments within 40 milliseconds from IC were adopted based on the previous study [22]. Simultaneously, frontal and sagittal plane views of the DVJ were acquired using high resolution video cameras (120 frames/s; Oqus, Qualisys, Sweden) to evaluate Landing Error Scoring System (LESS) score.

\section{Statistical analysis}

As a statistical analysis, non-repeated measures of ANOVA were used among groups. After $P$ value was less than 0.05 , post hoc Bonferroni correction was utilized for comparison and basketball players were used as controls. The statistical significance level was set at $P=0.05$. All statistical analyses were performed using SPSS ${ }^{\circledR}$ for Windows version 23 software (Microsoft, Chicago, IL).

\section{Results}

Athletes' data were shown in Table 1. There were no significant differences among groups except for age between basketball and soccer players. A total of 50 knees in 25 basketball players, 16 knees in 8 soccer players and 18 knees in 9 volleyball players, were analyzed.

Table 1

Athletes' data in each group (mean $\pm \mathrm{SD}$ )

\begin{tabular}{|lllll|}
\hline & Basketball & Soccer & Volleyball & PValue $^{\text {a }}$ \\
\hline Age $(\mathrm{yrs})$ & $20.4 \pm 1.4$ & $18.9 \pm 1.0 *$ & $20.6 \pm 1.1$ & 0.02 \\
\hline Height $(\mathrm{m})$ & $1.62 \pm 0.05$ & $1.60 \pm 0.05$ & $1.62 \pm 0.06$ & 0.53 \\
\hline Weight $(\mathrm{kg})$ & $55.4 \pm 4.9$ & $54.4 \pm 2.6$ & $53.9 \pm 6.1$ & 0.70 \\
\hline BMI $\left(\mathrm{kg} / \mathrm{m}^{2}\right)$ & $21.2 \pm 1.3$ & $21.3 \pm 0.8$ & $20.4 \pm 1.9$ & 0.31 \\
\hline${ }^{\text {a }}$ Values obtained using non-repeated measures of ANOVA & \\
${ }^{*} P<0.05$ between basketball and soccer players using post hoc Bonferroni correction \\
\hline
\end{tabular}

Kinematic and kinetic differences in each group were presented in Table 2 and 3, respectively. LESS score was $4.8 \pm 1.5$ in basketball players, $3.3 \pm 1.4$ in soccer players, and $6.0 \pm 2.8$ in volleyball players. LESS score was better in soccer players than in basketball players, while no significant differences were found between volleyball and basketball players. In addition, in soccer players, peak knee flexion angle was significantly larger compared to basketball players. Moreover, knee abduction angle at IC, peak knee abduction angle, knee internal rotation angle, and peak knee abduction moment within 40 milliseconds 
from IC were significantly smaller in soccer players than in basketball players. In terms of volleyball players, no significant kinematic and kinetic differences were found compared to basketball players.

Table 2

Kinematic differences in each group (mean \pm SD)

\begin{tabular}{|lllll|}
\hline & Basketball & Soccer & Volleyball & PValue $^{\mathrm{a}}$ \\
\hline LESS Score & $4.8 \pm 1.5$ & $3.3 \pm 1.4^{*}$ & $6.0 \pm 2.8$ & 0.013 \\
\hline Knee flexion angle at IC (Deg.) & $34.0 \pm 8.4$ & $36.7 \pm 7.6$ & $35.6 \pm 12.2$ & 0.54 \\
\hline Peak knee flexion angle (Deg.) & $99.3 \pm 12.0$ & $115.4 \pm 10.7^{*}$ & $98.7 \pm 15.1$ & 0.0001 \\
\hline Knee abduction angle at IC (Deg.) & $-0.8 \pm 6.5$ & $-7.2 \pm 6.4^{*}$ & $1.3 \pm 7.0$ & 0.0039 \\
\hline Peak knee abduction angle (Deg.) & $5.3 \pm 9.4$ & $-3.8 \pm 7.7^{*}$ & $3.1 \pm 8.4$ & 0.0028 \\
\hline Knee internal rotation angle at IC (Deg.) & $-3.5 \pm 11.5$ & $-14.2 \pm 8.4^{*}$ & $-0.9 \pm 14.4$ & 0.0024 \\
\hline Peak knee internal rotation angle (Deg.) & $4.6 \pm 7.7$ & $4.6 \pm 7.1$ & $6.3 \pm 8.2$ & 0.71 \\
\hline a Values obtained using non-repeated measures of ANOVA & & \\
* $P<0.05$ between basketball and soccer players using post hoc Bonferroni correction & \\
\hline
\end{tabular}

Table 3

Kinetic differences in each group (mean \pm SD)

\begin{tabular}{|c|c|c|c|c|}
\hline & Basketball & Soccer & Volleyball & $\begin{array}{l}P \\
\text { Value }\end{array}$ \\
\hline $\begin{array}{l}\text { Peak knee flexion moment within } 40 \mathrm{~ms} \text { from IC } \\
(\mathrm{Nm} / \mathrm{kg})\end{array}$ & $2.1 \pm 0.9$ & $2.1 \pm 0.8$ & $1.8 \pm 0.8$ & 0.55 \\
\hline $\begin{array}{l}\text { Peak knee abduction moment within } 40 \mathrm{~ms} \text { from IC } \\
(\mathrm{Nm} / \mathrm{kg})\end{array}$ & $\begin{array}{l}0.37 \pm \\
0.30\end{array}$ & $\begin{array}{l}0.16 \pm \\
0.30 *\end{array}$ & $\begin{array}{l}0.24 \pm \\
0.33\end{array}$ & 0.030 \\
\hline $\begin{array}{l}\text { Peak knee internal rotation moment within } 40 \mathrm{~ms} \\
\text { from IC }(\mathrm{Nm} / \mathrm{kg})\end{array}$ & $\begin{array}{l}0.24 \pm \\
0.33\end{array}$ & $\begin{array}{l}0.21 \pm \\
0.21\end{array}$ & $\begin{array}{l}0.30 \pm \\
0.37\end{array}$ & 0.65 \\
\hline \multicolumn{5}{|c|}{ a Values obtained using non-repeated measures of ANOVA } \\
\hline
\end{tabular}

\section{Discussion}

The results of the present study supported the hypothesis that biomechanical features would depend on the athlete's primary sport. The most important finding of the current investigation was that female basketball and volleyball players were likely to have the increased risk for non-contact ACL injury in DVJ, 
compared to soccer players [6]. Therefore, DVJ might be useless as a screening tool of non-contact ACL injury for soccer players.

The LESS score can be easily evaluated using frontal and sagittal plane views of video data. Therefore, the score has clinically been shown to be a convenient assessment tool of jump-landing biomechanics. Currently, the score during DVJ has been used to evaluate the risk factor for ACL injury of female athletes. Padua et al. suggested that 5 in LESS score was the optimal cut point, generating a sensitivity of $86 \%$ and a specificity of $64 \%$ for non-contact ACL injury [6]. From the present study, female basketball and volleyball players had worse LESS score, compared to female soccer players.

Regarding DVJ as a screening test of non-contact ACL injury, controversy still remains. Hewett et al. reported that female athletes with increased knee abduction angle or moment during DVJ would be prone to non-contact ACL injury as described before [1]. However, Krosshaug et al. indicated that DVJ could be a poor screening test for ACL injuries in their prospective cohort study [19]. The participant in Hewett's study were 205 female adolescent soccer, basketball, and volleyball players like the present study. On the other hand, those in Krosshaug's study were elite 372 handball players and 338 soccer players. Therefore, primary sporting activities were different between these studies. Furthermore, activity level was also different. Braun et al assessed ACL biomechanical risk factors in female field hockey and lacrosse players to determine whether sport-specific posture might contribute to the increased incidence of $A C L$ injury observed in lacrosse athletes [11]. They concluded that that decreased knee flexion angle during landing, consistent with sport-specific playing postures, may contribute to the higher incidence of $\mathrm{ACL}$ injury in lacrosse players relative to field hockey. Similarly, from the present study, significant differences of kinematic and kinetic changes were found among three different sporting activities.

Several limitations should be noted in the present study. First, the present study was done using college athletes with Tegner activity scale 7 to 9 . Thus, it is possible that the biomechanical parameters of high school or recreational athletes may be slightly different. Second, only three different sporting activities were included in the current study. The other kind of sports, like hockey, lacrosse, handball and so on, were still unknown. Lastly, although the risk of non-contact injury to the ACL was evaluated, the actual incidence of ACL injury could not be investigated. Nonetheless, the present results provide important information regarding the sport-specific characteristic of female knee kinematics and kinetics during jumping tasks.

\section{Conclusion}

Female basketball and volleyball players are likely to have the increased risk of non-contact ACL injury in jumping tasks, compared to soccer players. Biomechanics of DVJ depends on characteristics of the athlete's primary sport.

\section{Abbreviations}


ACL: Anterior cruciate ligament; DVJ: Drop vertical jump; GRF: Ground reaction force; IC: Initial contact; LESS: Landing error scoring system; ms: milliseconds; PKABDM: Peak knee abduction moment; PKFM: Peak knee flexion moment; PKIRM: Peak knee internal rotation moment; TO: Toe-off; vGRF: Vertical ground reaction force

\section{Declarations}

\section{Acknowledgements}

We acknowledge the contribution of the Keio female basketball team, Keio female soccer team, Keio Medical girls' basketball team, Keio Medical girls' volleyball team, Hiroo Osaki, Tomohiro Yanai, Keita Sonoda, Ryutaro Tanaka, Mayu Minemoto, Masayoshi Kurosawa, Rika Uchiyama, Ryuto Yoshida, Yuki Hoshi, Aiko Sakurai, Satoshi Imai, Ryoji Hayakawa and Sumi Yamashita for their help.

\section{Funding}

This study was not supported.

\section{Availability of data and material}

All supporting data can be provided based on request to the authors.

\section{Authors' contributions}

$\mathrm{KH}$ and $\mathrm{YM}$ collected data and prepared the manuscript. $\mathrm{KH}$ and TK conceived and design the study and assisted with the statistical analysis. SK and YN developed the study design and interpretation of data. YN and TN assisted in the coordination of the study and manuscript preparation. All authors read and approved the final manuscript.

\section{Ethics approval and consent to participate}

This study was approved by the institutional review board of Keio University School of Medicine (IRB No. 20080054 and 20190116) and participants provided written informed consent to participate. All methods were carried out in accordance with relevant guidelines and regulations.

\section{Consent for publication}

Not applicable.

\section{Competing interest}

None of the authors had any conflict of interest regarding this manuscript.

\section{Author details}


${ }^{1}$ Department of Orthopedic Surgery, Keio University School of Medicine, 35 Shinanomachi, Shinjuku-ku, Tokyo, 160-8582, Japan. ${ }^{2}$ Department of Clinical Biomechanics, Keio University School of Medicine, 35 Shinanomachi, Shinjuku-ku, Tokyo, 160-8582, Tokyo, Japan.

\section{References}

1. Hewett TE Myer GD, Ford KR, Heidt RS, Jr., Colosimo AJ, McLean SG, et al. Biomechanical measures of neuromuscular control and valgus loading of the knee predict anterior cruciate ligament injury risk in female athletes: a prospective study. Am J Sports Med. 2005;33:492-501.

2. Padua DA, Marshall SW, Boling MC, Thigpen CA, Garrett WE, Jr., Beutler Al. The Landing Error Scoring System (LESS) Is a valid and reliable clinical assessment tool of jump-landing biomechanics: The JUMP-ACL study. Am J Sports Med. 2009;37:1996-2002.

3. Bates NA, Ford KR, Myer GD, Hewett TE. Timing differences in the generation of ground reaction forces between the initial and secondary landing phases of the drop vertical jump. Clin Biomech (Bristol, Avon). 2013;28:796-9.

4. Dingenen B, Malfait B, Nijs S, Peers KH, Vereecken S, Verschueren SM, et al. Can two-dimensional video analysis during single-leg drop vertical jumps help identify non-contact knee injury risk? A oneyear prospective study. Clin Biomech (Bristol, Avon). 2015;30:781-7.

5. Nyman E, Jr., Armstrong CW. Real-time feedback during drop landing training improves subsequent frontal and sagittal plane knee kinematics. Clin Biomech (Bristol, Avon). 2015;30: 988-94.

6. Padua DA, DiStefano LJ, Beutler Al, de la Motte SJ, DiStefano MJ, Marshall SW. The Landing Error Scoring System as a Screening Tool for an Anterior Cruciate Ligament Injury-Prevention Program in Elite-Youth Soccer Athletes. J Athl Train. 2015;50:589-95.

7. Dingenen B, Malfait B, Vanrenterghem J, Robinson MA, Verschueren SM, Staes FF. Can twodimensional measured peak sagittal plane excursions during drop vertical jumps help identify threedimensional measured joint moments? Knee. 2015;22:73-9.

8. Husted RS, Bencke J, Andersen LL, Myklebust G, Kallemose T, Lauridsen HB, et al. A comparison of hamstring muscle activity during different screening tests for non-contact $A C L$ injury. Knee. 2016;23:362-6.

9. Munro A, Herrington Herrington L. The effect of videotape augmented feedback on drop jump landing strategy: Implications for anterior cruciate ligament and patellofemoral joint injury prevention. Knee. 2014;21:891-5.

10. Nichols JK, O'Reilly OM. Verifying the equivalence of representations of the knee joint moment vector from a drop vertical jump task. Knee. 2017;24:484-490.

11. Braun HJ, Shultz R, Malone M, Leatherwood WE, Silder A, Dragoo JL. Differences in ACL biomechanical risk factors between field hockey and lacrosse female athletes. Knee Surg Sports Traumatol Arthrosc. 2015;23:1065-70. 
12. Taylor JB, Nguyen AD, Shultz SJ, Ford KR. Hip biomechanics differ in responders and non-responders to an ACL injury prevention program. Knee Surg Sports Traumatol Arthrosc. 2018.

13. Hewett TE, Myer GD, Kiefer AW, Ford KR. Longitudinal Increases in Knee Abduction Moments in Females during Adolescent Growth. Med Sci Sports Exerc. 2015;47:2579-85.

14. Malfait B, Sankey S, Firhad Raja Azidin RM, Deschamps K, Vanrenterghem J, Robinson MA, et al. How reliable are lower-limb kinematics and kinetics during a drop vertical jump? Med Sci Sports Exerc. 2014;46:678-85.

15. Cesar GM, Tomasevicz CL, Burnfield JM. Frontal plane comparison between drop jump and vertical jump: implications for the assessment of ACL risk of injury. Sports Biomech. 2016;15:440-9.

16. Mueske NM, Patel AR, Pace JL, Zaslow TL, VandenBerg CD, Katzel MJ, et al. Improvements in landing biomechanics following anterior cruciate ligament reconstruction in adolescent athletes. Sports Biomech. 2018:1-12.

17. Satkunskiene D, Kamandulis S, Brazaitis M, Snieckus A, Skurvydas A. Effect of high volume stretchshortening cycle exercise on vertical leg stiffness and jump performance. Sports Biomech. 2018:117.

18. Cruz A, Bell D, McGrath M, Blackburn T, Padua D, Herman D. The effects of three jump landing tasks on kinetic and kinematic measures: implications for ACL injury research. Res Sports Med. 2013;21:330-42.

19. Krosshaug, T, Steffen K, Kristianslund E, Nilstad A, Mok KM, Myklebust G, et al. The Vertical Drop Jump Is a Poor Screening Test for ACL Injuries in Female Elite Soccer and Handball Players: A Prospective Cohort Study of 710 Athletes. Am J Sports Med. 2016;44:874-83.

20. Simons C, Bradshaw EJ. Reliability of accelerometry to assess impact loads of jumping and landing tasks. Sports Biomech. 2016;15:1-10.

21. Whyte EF, Kennelly P, Milton O, Richter C, O'Connor S, Moran KA. The effects of limb dominance and a short term, high intensity exercise protocol on both landings of the vertical drop jump: implications for the vertical drop jump as a screening tool. Sports Biomech. 2018;17:541-553.

22. Morishige $Y$, Harato K, Kobayashi S, Niki Y, Matsumoto M, Nakamura M, Nagura T: Difference in leg asymmetry between female collegiate athletes and recreational athletes during drop vertical jump. $J$ Orthop Surg Res 2019;14:424.

\section{Figures}




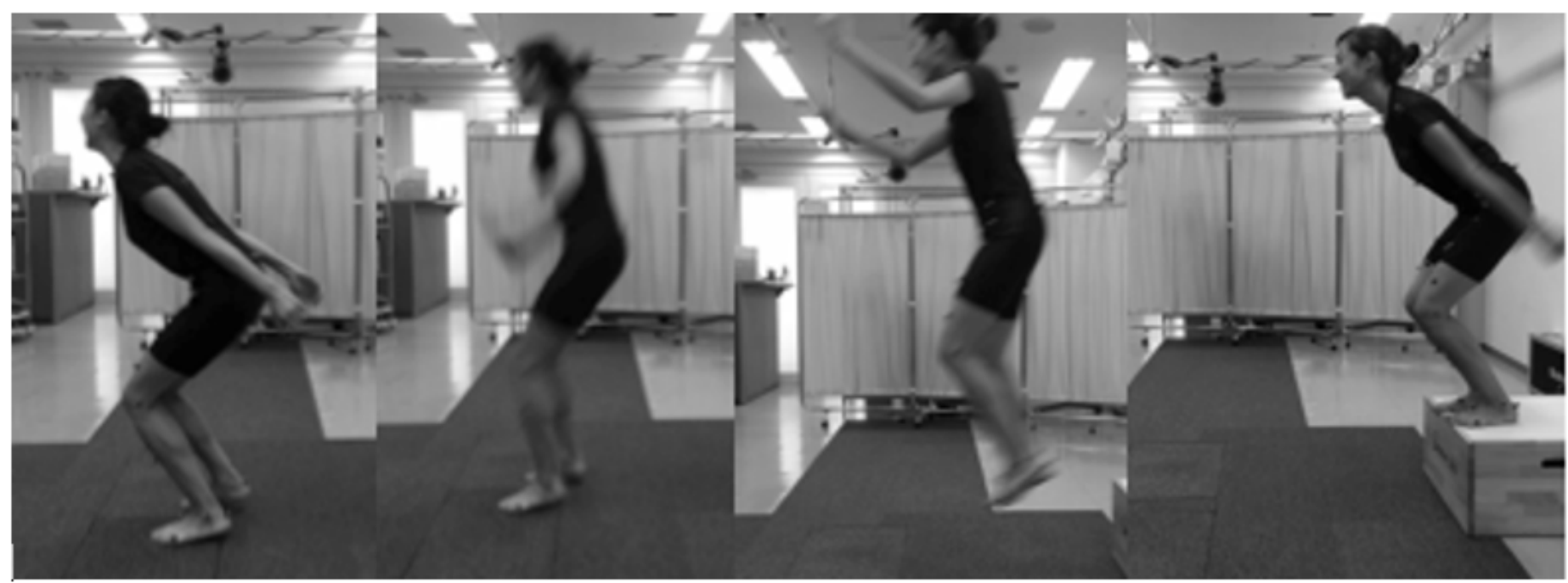

\section{Figure 1}

Female athletes performed drop vertical jump (DVJ) which as jumping from a 30-cm high box onto force plates positioned $50 \%$ of the height of each athletic away from the box, and immediately rebounding on landing into a maximal vertical jump. 


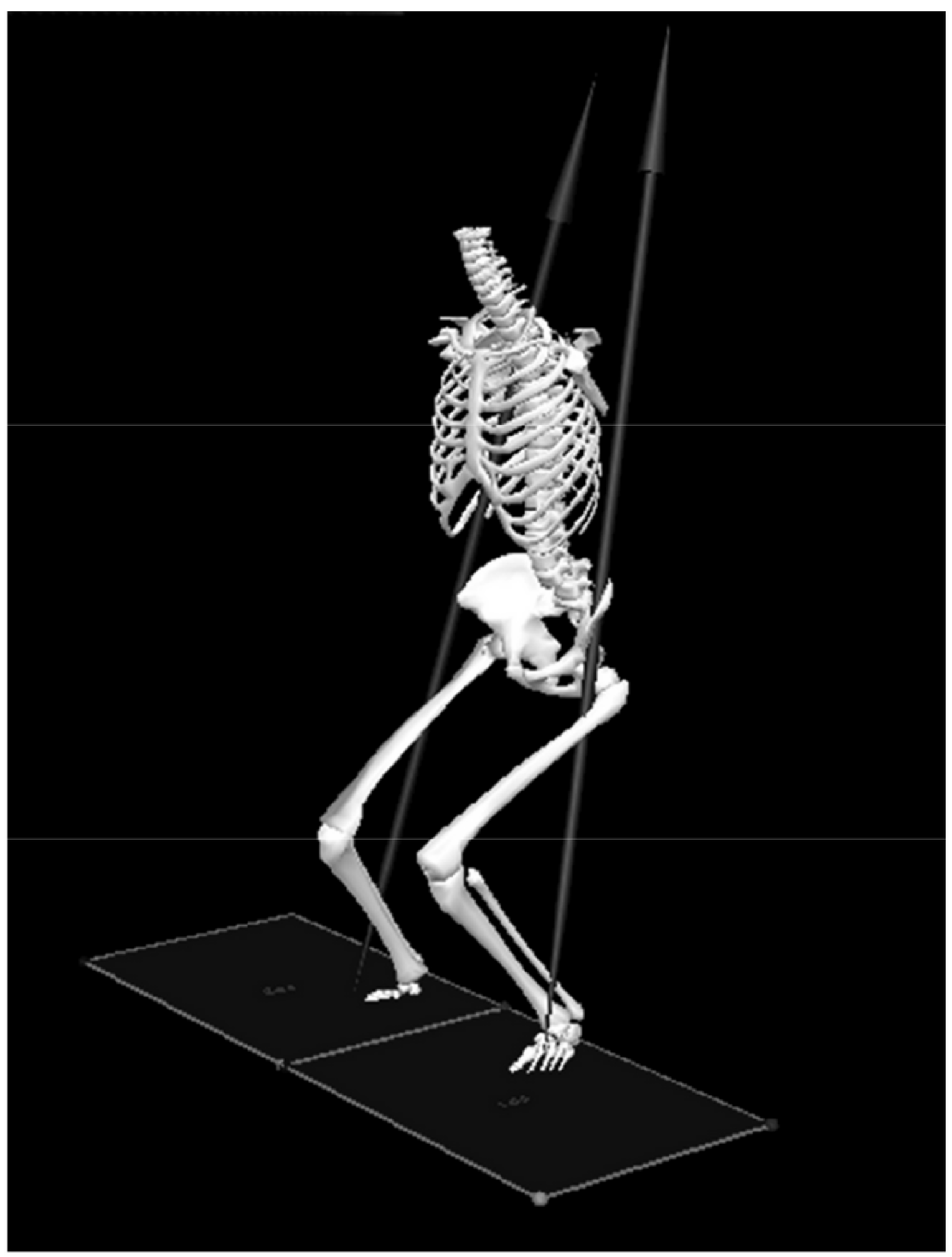

Figure 2

Three-dimensional knee kinematics and kinetics were calculated during initial contact (IC) to Toe-off (TO) in DVJ. 